\title{
The Most Important Functional and Non-Functional Requirements of Knowledge Sharing System at Public Academic Institutions: A Case Study
}

\author{
Saad Alsaleh and Haryani Haron
}

\begin{abstract}
This qualitative study aims to explore and describe the most important functional requirements (FR) and non-functional requirements (NFR) of knowledge sharing system (KSS) used at a Malaysian public academic institution. The strategy used is a single case study which aims to gather deeper insights on the requirements of the KSS. Data were collected through semi-structured interviews. A total of fifteen renowned academicians were interviewed. Content analysis method was used to extract the requirements from the qualitative data. The study identified twelve FR and NFR that academicians as an end users believe should be included in the KSS. The FR include alert user about new added; be able to categorize contents, have an efficient search process; offer information about experts; offer a consultation service; and provide interconnections among disciplines. The NFR include support multi-media, ensure accessibility; provide interactivity; be reliable; easy to use; and multi-level. The research comprehensive analysis and findings would expand an area of systems FR and NFR being used for knowledge sharing in academic institutions which may still theoretically and empirically not sufficiently covered.
\end{abstract}

Index Terms-Academicians, functional requirement, non-functional requirement, knowledge sharing system.

\section{INTRODUCTION}

Recently, there have been an important advances in computing technologies, and software assumed a central role in the control of equipment's, devices and processes based on systems [1]. Numerous organizations have adopted Information Technology applications [2] including academic institutions [3]. It has been argued that organizations often do not know or understand what they actually need until they invest heavily in a system that fails to provide it [4]. According to [5], the development of a system is not just a method of designing algorithms and database structures; it is also about knowing and understanding the needs of the users within the organizations to ensure that the system meets user needs. Reference [5] emphasized the need to understand the organizational environment within which the new system is intended to operate. In addition, the requirements are not always consistent, hence, interacting with the stakeholders can help to resolve these inconsistences [6].

Manuscript received October 15, 2014; revised January 5, 2015.

Saad Alsaleh is with General Directorate of Health Affairs in Hail, Ministry of Health, Hail, Saudi Arabia (e-mail: captiansaadasa@yahoo.com).

Haryani Haron is with Faculty of Computer and Mathematical Science, University Technology Mara (UiTM) Shah Alam, Malaysia (e-mail: haryani@tmsk.uitm.edu.my).
Additionally, the productivity of professionals responsible for systems development will be increased and the quality of the delivered system greatly enhanced if the systems link directly to the user requirements [7]. Therefore, the effective discovery and analysis of requirements is one of the most important steps in the life cycle any software system [8].

Given the current problem of understanding requirements and needs of the sharing system in academic intuitions, this research aims to explore and determine the system requirements from the academicians perspective as an end user of the system.

\section{LITERATURE REVIEW}

\section{A. System Requirement Concept and Types}

Requirement engineering is a very important phase of a software development [9]-[11], but it is often neglected activity during the development process [12]. The conventional view of requirements definition is that this phase of systems development begins with an informal description of "what" the system is expected to do [5], [6]. As has been explained by [13], one of the major tasks in designing systems development is the systematic elaboration of system requirements. Determine the right requirements for the system is a very critical in the system development life, hence, there is a need to consider this phase carefully. References [3] and [14] contended that the requirement is one of the most critical stages in the development life cycle of any new system, thus, it should be carefully implemented to build high quality and reliable system.

There are four tasks for requirement engineering were presented by [15] included requirements elicitation, requirements negotiation, requirements specification, and requirements validation. The elicitation task is considering the organizational environment and situation that the system aims to improve and describing both the needs as well as constraints concerning the system under development. The main aim of the negotiation task is to form an agreement on the requirements of the system among many types of users involved in the process. Requirements specification task contains a mapping of real needs onto a requirements model. However, the broader view on requirement engineering proposes that the requirements specification goes beyond the traditional approach which focuses on functional requirements modeling and includes the modeling of the enterprise context which provides the aim of the intended system. The last engineering requirement task is the 
validation which intends to ensure that the derived specification corresponds to the original user needs and conforms to the internal and external constraints set by the enterprise and its environment.

This study focused on the first task, namely, the elicitation requirement. The requirements engineering process starts with the elicitation of requirements [13]. In this study, the elicitation defined as extracting and/or discovering the needs of end users from the system. One of the most important tasks in the requirement engineering is the elicitation task, hence, the poor implementation of elicitation will almost guarantee that the final system project is a complete failure and the key measure of system success is the degree to which it meets its intended purpose [16], [17].

Two main types of requirements involved in developing any new system, namely, Functional Requirement (FR) which include user needs from the system and Non-Functional Requirement (NFR) which represent system architecture. As stated by [13], users' requirements and the system's constraints set up the entirety both FR as well as NFR that have to be met as a pre-requirement for successful system projects. Additionally, to be able to keep these requirements, it has to be ensured that they are completely elicited and documented to know them in their entirety without ambiguities, incorrectness, or contradictions in an up-to date status [13].

The FR defined as a "behavior of the intended system and their representation can be done by a precise, mathematical, functional description" [13]. Another definition for the FR is "A requirement that specifies an action that a system must be able to perform, without considering physical constraints; a requirement that specifies input/output behavior of a system" [18]. The FR describes the user functionalities of the future system, and general conditions specify restrictions or design decisions to be observed in the development [13]. In this study, the FR defined as a function that a system must be able to perform.

On the other hand, although the term NFR has been in use for more than two decades, there is still no unanimity in the requirements engineering community what NFRs are and how to elicit and document them [19]. For example, the NFR has been defined by [13] as a property or quality that the product must have (such as an appearance, or a speed or accuracy property) whereas it according to [20] describe the non-behavioral aspects of a system, capturing the properties and constraints under which a system must operate. The NFR may include also some features such as portability, reliability, efficiency, human engineering, testability, understandability, and modifiability [21], maintainability, extensibility, and reliability [18]. For the purpose of this study, the NFR defined as how the system should perform the tasks.

Even though that the NFR are often underestimated or ignored [22] there is a common consensus that NFR are essential and can be critical for the success of a system project [6], [10], [19], [23]-[25]. Furthermore, to achieve a high quality software system, both FR and NFR should be addressed [12], [26]. Therefore, in this study both types of requirements have been taken into confederation.

\section{B. System Software Development}

According to [1] the software development teams are concerned with the development of systems that address user needs while it as [27] an "activity of creating a software system that when used, solves some hitherto unsolved problem". System software development is getting more mature by advancing development processes, methods, and tools [28]. Nevertheless, the software industry has the challenge of developing a great variety of software products with improving quality and decreasing costs [29]. In addition, [28] mentioned that the investigation of system software projects has shown that requirements analysis is one of the most problematic activities in system software development. Moreover, system software development literature is abounding with studies that demonstrate how ineffective requirements analysis has led to failed applications [30]. For these reasons, set out successful requirements process in a concrete organization is a vital issue [28].

\section{METHODOLOGY}

The approach of this case study was descriptive form of qualitative research. This approach has been chosen because the aim of this study was to comprehensively explore and identify in-depth both FR and NFR of a knowledge sharing system (KSS) from academic staff as end users, thus, a case study with qualitative method was most appropriate. "In Information Systems, there has been a general shift in information system research away from technological to managerial and organizational issues, hence an increasing interest in the application of qualitative research methods" [22]. As [31], in terms of generating a better understanding of the use of the information system, qualitative research has been found to be a successful approach and method to achieve that. For the study site, it has been chosen because it is one of the largest universities in the country with almost 480 academic programs by coursework as well as research modes, hence, that would offer high opportunities for richly and deeply explore and identifying the various system requirements that its academic staff really needs.

A purposeful technique was used to determine the research participants who can answer the research question. The purposeful technique in a qualitative study enables the researcher to select the most productive sample in order to answer questions of research [32]. To minimize the bias threat in this research, a high level of integrity has been done. For instance, during the invitation period, all potential participants had informed that they have a full freedom to deny or accept participation. Those who agree to participate, they had a choice to determine the appropriate place as well as time to hold the interview. The data were collected through conducted a semi-structured interview. One of the most common techniques to acquire the requirement is conducting interviews with the end users [18]. The data were collected over six months with fifteen renowned academicians at one public universities in Malaysia. Two participants' having an Associate Professor positions' and thirteen having a Professor positions', three of them are faculty deans. The participants work in various faculties and disciplines. Although the participants work in different faculties, the conclusion is that they have been a homogeneous participant group because all 
of them were academicians and there was no any non-academic staff involved.

The interviews continued until the participants no longer provide differing information, and data saturation developed in the answers. According to [33], the criterion of saturation determines the theoretical point at which adequate data have been generated, thus, the number of individuals to be included In addition, in qualitative research, the sample size is usually small [34], [35]. The interview question focused and developed based on understanding the research problem through reviewing and examining of related literatures. Reference [15] explained that the qualitative researcher "do not tend to use or rely on questionnaires or instruments developed by other researchers"

It was emphasized that when conducting a qualitative research, the researcher should consider the finding validity [14]. For this study, to ensure the validity of the findings, steps were taken in a credible scholarly. Some strategies to promote qualitative research validity have introduced by [36]. Two strategies to promote qualitative validity have been used in this study. These strategies were the Low Inference Descriptor and Data Triangulation. Table I illustrates these strategies.

TABLE I: QUALITATIVE RESEARCH VALIDITY STRATEGIES

\section{Strategy}

\begin{tabular}{ll}
\hline $\begin{array}{c}\text { Low } \\
\text { Inference }\end{array}$ & $\begin{array}{l}\text { The use of Description phrased very closed to } \\
\text { the participants' accounts and researchers' field } \\
\text { Descriptor }\end{array}$ \\
$\begin{array}{l}\text { notes. Verbatim (i.e. Direct quotations) is a } \\
\text { commonly used type of low inference descriptor }\end{array}$ \\
$\begin{array}{l}\text { The use of multiply data sources to help } \\
\text { Triangulation }\end{array}$ & understand a phenomenon. \\
\hline \hline
\end{tabular}

\section{DATA ANALYSIS}

The academicians were asked what they considered to be the important requirements or features which should to be included in a KSS at academic institutions. After collecting data from the study participants, an open coding analysis of the data has been conducted. As a qualitative research with a case study approach, the study procedure establishes analyzing and coding of the participants' responses to the research question. In the coding process, the interviews taped responses were transcribed into textual then reviewed many times to identify the concepts and types of the system requirements. The analyzing and coding of responses was line-by-line. The main requirements were identified through free coding into categories. The qualitative researcher engages in interpreting the data when they conduct qualitative research. Reference [17] mentioned that the qualitative researcher "review all of the data and make sense of it, organizing it into categories or themes". The categorization process has been done based on the type of each requirement (either FR or NFR) as it seems the best description of the system requirement types. According to [27] "Code labels emerge from several sources. They might be in vivo codes, names that are the exact words used by participants...they might be also drawn from names the researcher composes that seem to best describe the information".

\section{FINDINGS AND DISCUSSION}

\section{A. Functional Requirements}

The first FR is alerting users about new added. This service is available in some system under name 'Rich Site Summary' (RSS). The academicians recommended to add such service in the KSS to provide them with an update and frequently publish knowledge. Included such service in the KSS would save academicians effort and reduce time as this service will remove the need to manually check the system for new content. Instead, the system constantly monitors the system and informs them of any updates. The second important requirement is offering a consultation service. The academicians believe that the system should be provided by a consultation service which enable them to consult experts and obtain assistance in their area or interest. Besides, in the university, the consultation might involve a collegial relationship in which the consultant deals exclusively with academicians work-related (including educational, training, and organizational) or student issues. For instance, the academicians my request educational and training consultation to supplement their skills and knowledge. That my include training labs, conference, seminars, workshop, and supervision. Organizational consultation assesses and improves the academicians interpersonal and group functioning within academic institutions. The consultant serves as a facilitator to focus on such areas as communication, decision making, team relations, and conflict resolution. Specific services include needs assessment, team building, and process observation.

The third requirement is offering information about experts in the system. This service can be achieved through collecting and adding the list of expert information in the system. However, as the list might include hundreds name of experts, and to make the searching process easier, they can be classified based on their expertise area. The fourth requirement which suggested by participants is providing the system by interconnections among disciplines (be able to connect academicians from different disciplines). This requirement should available in the KSS because the university has many faculties and departments and each of them usually has a different discipline. The fifth requirement is that the system should offer an efficient search engine. Offering such engine, particularly with huge amount of data, is essential. Using a search engine consists of entering keywords that are run against a database. Some features of effective search engine could be related to its ability to search and display only very close relevant results (results the academicians actually interested in), helpful options to broaden or tighten a search, uncluttered, and easy to read interface. The last FR is the accessibility. The accessibility can be seen from different perspectives. Generally, it is the degree to which the KSS is available to as many academicians and their networks as possible. Besides, it can be viewed as the "ability to access" and benefit from the system or entity. Both of views should be considered for the KSS in the academic institutions. Ensuring accessibility is very essential in any effective and successful KSS as it enables users from different areas, different place, and at a different time to engage, exchange, and utilize valuable knowledge. 


\section{B. Non-Functional Requirements}

The first NFR is the categorization of system contents. There are several benefits of categorizing system content include: ensuring that users can easily navigate, browse, and search the system content. Some ways for categorizing system content include categorize it by subject, by topic, by task, by service, by audience group, by geographic location, or by any combination of these factors. However, one of the most categorization methods is that organizing content based on the academicians subjects because it will be more meaningful and understandable. In other words, they will be familiar with navigating system by their own subjects. If the academician familiar with the categorization of the system content, that will make their browning of all contents easier as well as reducing the navigation time and effort. The second requirement which academicians believe it is important is the interactivity. Interactive systems can be defined as systems whose operations involve a significant degree of user interaction. In other words, it is the dialog that occurs between a user and a system. Some participants suggested this feature with the aim of overcoming or finding a solution for any problem they may face in future. As an example of support is that the system should enable them to request help from technician support when any error occurs.

The third important requirement is the system reliability. Reliability is an attribute of any system component that consistently performs according to its specifications. The KSS should be reliable for important reasons. Firstly, the university has hundreds or thousands (depend on the university size and workforce) of academic staff distributed in its several faculties and departments. In addition, because the academicians may willing to share through the system with other academicians at other local or international academic as well as with other associates in non-educational government and private organizations.

Easy to use the system is also a NFR which suggested by the participants. This might include browsing of system contents should be done with a minimum effort and time. Also, it could include that gives the academician full control over his own account. For instance, the system allows him to manage all content, functionality, and navigation in a single interface. The fifth requirement is that the system should be a multilevel. Multilevel means that the system should enable academicians to communicate via more than one channel based on their relationship, interest, or departments. For example, the system should enable the academician if he wants to share a certain issues with only those who knows, teach same discipline, or work in his faculty. Certain knowledge he does not willing to share with everybody. In the workplace, for instance, the system can be designed a multilevel based on faculty level; university level, or a specific organization type. Finally, the system should support multimedia. Multimedia refers to that the system should be able to deal with content that uses a combination of different content forms. The forms may include a combination of text, audio, images, video, animation, or interactivity content forms. The various formats of technological or digital multimedia may enhance the academicians' experience, for example, to make it easier and faster to convey knowledge.

\section{CONCLUSION AND FUTURE WORK RECOMMENDATIONS}

This study identified twelve FR and NFR that should be available in the KSS in academic institutions. It extends prior research on knowledge system requirements in academic institutions, particular, universities. The study findings might provide useful insights for the administrations of universities to consider these requirements for their knowledge management and sharing system to be linked with the real needs of their academic staff. However, these findings cannot be generalized to represent all academic institutions as this study admitted a qualitative research and conducted at a single public university. As this research focused on the solely KSS requirements from academicians perspectives, it is recommended for future research to explore and determine requirements from the other staff perspective such as, for example, non-academic staff.

\section{ACKNOWLEDGMENT}

The authors of this research paper introduce their thankfulness to the Saudi Ministry of Higher Education for their moral support and encouragement.

\section{REFERENCES}

[1] L. E. G. Martins and T. de Oliveira, "A case study using a protocol to derive safety functional requirements from fault tree analysis," in Proc. 2014 IEEE 22nd International on Requirements Engineering Conference (RE), 2014, pp. 412-419.

[2] S. Sarker, S. Gasson, and C. Haythornthwaite, "Information and communication technologies in support of knowledge management/organizational memory/organizational learning," presented at the System Sciences, 2005.

[3] B. Boehm and V. R. Basili, "Software defect reduction top 10 list," Foundations of Empirical Software Engineering: The Legacy of Victor R. Basili, 2005, p. 426.

[4] F. V. Assche, P. Layzell, P. Loucopoulos, and G. Speltincx, "Information systems development: A rule-based approach," Knowledge-Based Systems, 1988, pp. 227-234.

[5] P. Loucopoulos and E. Kavakli, "Enterprise modelling and the teleological approach to requirements engineering," International Journal of Cooperative Information Systems, vol. 4, no. 1, pp. 45-79, 1995.

[6] V. Lakshminarayanan, W. Liu, C. L. Chen, S. Easterbrook, and. E. Perry, "Software architects in practice: Handling requirements," in Proc. the 2006 Conference of the Center for Advanced Studies on Collaborative Research, IBM Corp, 2006, p. 25.

[7] E. Brinksma, D. Harel, A. Mader, P. Stevens, and R. Wieringa, A Model-Based Approach To Requirements Analysis Methods.

[8] T. H. Davenport and L. Prusak, Working Knowledge: How Organizations Manage What They Know, Harvard Business Press, 2000.

[9] Y. Sedelmaier and D. Landes, "Using business process models to foster competencies in requirements engineering," in Proc. 2014 IEEE 27th Conference on Software Engineering Education and Training (CSEE\&T), 2014, pp. 13-22.

[10] F. Z. Hammani, "Survey of non-functional requirements modeling and verification of software product lines," in Proc. the 2014 IEEE Eighth International Conference on Research Challenges in Information Science, 2014, pp. 1-6.

[11] M. R. Tabassum, M. S. Siddik, M. Shoyaib, and S. M. Khaled, "Determining interdependency among non-functional requirements to reduce conflict," in Proc. the 2014 International Conference on Informatics, Electronics \& Vision, 2014, pp. 1-6.

[12] M. Dabbagh, S. P. Lee, and R. M. Parizi, "Application of hybrid assessment method for priority assessment of functional and non-functional requirements," in Proc. the 2014 International Conference on Information Science and Applications, 2014, pp. 1-4.

[13] M. Glinz, "On non-functional requirements," in Proc. the 15th IEEE International Conferences on Requirements Engineering, 2007, pp. 21-26. 
[14] D. Aceituna, H. Do, G. S. Walia, and S. W. Lee, "Evaluating the use of model-based requirements verification method: A feasibility study," First International Workshop on Empirical Requirements Engineering, pp. 13-20, 2011.

[15] K. Pohl, Process-Centered Requirements Engineering, Taunton, Somerset, England, Research Studies Press Ltd, 1996.

[16] H. Jain, P. Vitharana, and F. M. Zahedi, "An assessment model for requirements identification in component-based software development," ACM SIGMIS Database, vol. 34, no. 4, 2003, pp. 48-63.

[17] J. W. Creswell, Qualitative Inquiry and Research Design: Choosing Among Five Approaches, SAGE Publications, p. 45, 2007.

[18] P. Loucopoulos and V. Karakostas, System Requirements Engineering, McGraw-Hill, Inc., 1995.

[19] W. Mayrhofer, M. Meyer, J. Steyrer, J. Maier, K. Langer, and A. Hermann, "International career habitus-thick descriptions and theoretical reflections," Academy of Management Annual Meeting Symposium on Global Careers and Human Resource Development: Emerging IHRM Perspectives New Orleans, USA, 2004.

[20] S. Robertson and J. Robertson, Mastering the Requirements Process: Getting Requirements Right, Addison-Wesley.

[21] A. M Davis, Software Requirements: Objects, Functions, and States, Prentice-Hall, Inc., 1993

[22] M. D. Myers and D. Avison, "Qualitative research in information systems," Management Information Systems Quarterly, vol. 21, pp. 241-242, 1997.

[23] H. W. Jung, S. G. Kim, and C. S. Chung, "Measuring software product quality: A survey of ISO/IEC 9126," IEEE software, vol. 21, no. 5, pp. $88-92,2004$

[24] X. L. Zhang, C. Ding, and R. K. Wong, "Non-functional Requirement Analysis and Recommendation for Software Services," in Proc. 2013 IEEE 20th International Conference on Web Services (ICWS), 2013, pp. 555-562.

[25] A. Bouain, A. El Fazziki, and M. Sadgal, "Integration of non-functional requirements in a service-oriented and model-driven approach," in Proc. the 2014 IEEE Eighth International Conference on Research Challenges in Information Science, 2014, pp. 1-8.

[26] A. Rashwan, O. Ormandjieva, and R. Witte, "Ontology-based classification of non-functional requirements in software specifications: A new corpus and SVM-based classifier," in Proc. 2013 IEEE 37th Annual Conference on Computer Software and Applications, 2013, pp. 381-386.

[27] A. M. Hickey and A. M. Davis, "Requirements elicitation and elicitation technique selection: model for two knowledge-intensive software development processes," in Proc. the 36th Annual Hawaii International Conference on System Sciences, 2003, p. 10.

[28] D. Silingas and R. Butleris, "UML-intensive framework for modeling software requirements," in Proc. the 14th International Conference on Information and Software Technologies, 2008, pp. 334-342.

[29] P. Santos-Neto, R. Resende, and C. Pádua, "Requirements for information systems model-based testing," in Proc. the 2007 ACM symposium on Applied computing, 2007, pp. 1409-1415.
[30] J. Aranda, S. Easterbrook, and G. Wilson, "Requirements in the wild How small companies do it," in Proc. 15th IEEE International Conference on Requirements Engineering, 2007, pp. 39-48.

[31] J. Nandhakumar, "Theory and thick descriptions: Personal reflections," Quality and Impact of Qualitative Research, p. 3.

[32] M. N. Marshall, "Sampling for qualitative research," Family Practice, vol. 13, no. 6, pp. 522-526, 1996.

[33] B. J. Jennings, "Factors that contribute to knowledge sharing within research based organizations," ProQuest Dissertations and Theses, 2001.

[34] F. Ryan, M. Coughlan, and P. Cronin, "Step-by-step guide to critiquing research. Part 2: qualitative research," British Journal of Nursing, vol. 16, no. 12, pp. 738-744, 2007.

[35] R B. H. Kwasnik, "The role of classification in knowledge represantation and discovery," Library Trends, vol. 48, no. 1, pp. $22-47$.

[36] R. B. Johnson, "Examining the validity structure of qualitative research," Education, vol. 118, no. 2, 1997, pp. 282-292.

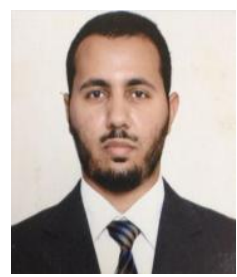

Alsaleh Saad was born in Hail city, located in the north-west of the Saudi Arabia Kingdom. He was born in 1980. Saad currently is a PhD student at the Faculty of Computer and Mathematical Sciences, University Technology Mara (UiTM) in Malaysia. Saad attained a master degree of science in information technology with honor from the University Technology Mara (UiTM) in Malaysia in 2011. In 2008, Saad acquired a bachelor degree in computing and information technology from the Arab Open University in Riyadh, the capital city of Saudi Arabia.

His experience of work started in 2000 at the Saudi Health Ministry. In 2011, he was appointed as an IT executive officer at the Department of Information Technology in the General Directorate of Health Affairs in Hail city, Saudi Arabia.

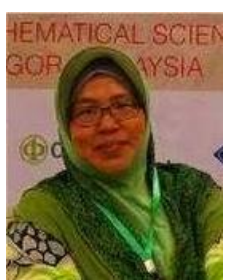

Haryani Haron is a Malaysian and earned her $\mathrm{PhD}$ in computer science from University Technology Malaysia, Johore, in 2009. She is currently an associate professor attached to the Faculty of Computers and Mathematical Sciences at the Universiti Teknologi MARA Malaysia, Shah Alam, Selangor. Her publications include chapters in a book, indexed journals and proceedings. Her specialization area in research is knowledge management, social and organizational informatics, and information systems. Associate Prof. Dr Haryani Haron is a member in IEEE Malaysian Society, Association of Information Systems (AIS) and IACSIT. Her research are currently supported by the Malaysian Ministry of Education with an accumulated grant totaling to nearly RM 300,00 besides from the university totaling. 